OPEN ACCESS

Edited by:

Katherine MacRae Dell, Cleveland Clinic Children's,

United States

Reviewed by:

Shashi Kumar Nagaraj, Duke University Medical Center, United States Gaurav Kapur, Children's Hospital of Michigan, United States

*Correspondence:

Muhammad Yazid Jalaludin yazidj@ummc.edu.my

Specialty section:

This article was submitted to Pediatric Nephrology,

a section of the journal

Frontiers in Pediatrics

Received: 13 September 2019 Accepted: 23 March 2020 Published: 15 April 2020

Citation: Abu Bakar K, Khalil K, Lim YN, Yap YC, Appadurai M, Sidhu S, Lai CS, Anuar Zaini A, Samingan N and Jalaludin MY (2020) Adrenal Insufficiency in Children With

Nephrotic Syndrome on

Corticosteroid Treatment. Front. Pediatr. 8:164 doi: 10.3389/fped.2020.00164

\section{Adrenal Insufficiency in Children With Nephrotic Syndrome on Corticosteroid Treatment}

\author{
Karmila Abu Bakar 1,2, Khairunnisa Khalit 2,3, Yam Ngo Lim², Yok Chin Yap ${ }^{2}$, \\ Mirunalini Appadurai ${ }^{2}$, Sangeet Sidhu ${ }^{2}$, Chee Sing Lai ${ }^{2}$, Azriyanti Anuar Zaini ${ }^{1}$, \\ Nurshadia Samingan ${ }^{1}$ and Muhammad Yazid Jalaludin ${ }^{1 *}$ \\ ${ }^{1}$ Pediatric Unit, Faculty of Medicine, University of Malaya, Kuala Lumpur, Malaysia, ${ }^{2}$ Pediatric Institute of the Hospital, Kuala \\ Lumpur, Malaysia, ${ }^{3}$ Paediatric Nephrology Unit, Institute of Paediatrics, Kuala Lumpur, Malaysia
}

Background: Adrenal insufficiency can result from impaired functions at all levels of hypothalamic-pituitary-adrenal (HPA) axis. We here studied risk factors associated with adrenal insufficiency in children receiving prolonged exogenous steroid treatment for nephrotic syndrome.

Method: We performed low-dose Synacthen tests (LDSTs, $0.5 \mu \mathrm{g} / \mathrm{m}^{2}$ ) in children with steroid-sensitive nephrotic syndrome 4-6 weeks after discontinuation of the corticosteroid therapy. We measured early morning serum cortisol levels at baseline and at intervals of 10,20,30, and 60 min following the stimulation test. We defined normal HPA axis stimulation responses as those with peak cortisol cut-off values $>550 \mathrm{nmol} / \mathrm{L}$.

Result: We enrolled 37 children for this study research. All children enrolled had normal early morning cortisol levels. However, 13 (35.1\%) demonstrated HPA axis suppression (by LDST) 4-+6 weeks after discontinuation of oral prednisolone. Nephrotic syndrome diagnosed before 5 years of age (OR, 0.75; 95\% Cl, 0.57-0.99; $p=0.043$ ), and steroid-dependence [OR, 5.58; 95\% confidence interval (Cl), 1.06-29.34; $p=0.042$ ] were associated with increased risk of developing adrenal suppression after steroid discontinuation.

Conclusion: HPA axis suppression, may go unnoticed without proper screening. A normal early morning cortisol level (275-555 nmol/L) does not exclude adrenal insufficiency in children with steroid-sensitive nephrotic syndrome. Further screening with LDSTs, particularly in children younger than 5 years at diagnosis, may be warranted.

Keywords: adrenal insufficiency, steroid withdrawal, nephrotic syndrome, HPA axis, cortisol, low-dose Synacthen test, adrenal suppression

\section{INTRODUCTION}

The most common glomerular disease in childhood is idiopathic nephrotic syndrome (NS), for which corticosteroids are the first line of treatment. Almost $80 \%$ of children with NS demonstrate steroid responsiveness, achieving complete remission within 4 weeks. However, $\sim 40-50 \%$ of these children are steroid dependent and require a long course of steroids, leaving them vulnerable to the adverse effects of chronic steroid usage, such as stunted growth, hypertension, obesity, secondary diabetes, vitamin $\mathrm{D}$ deficiency and secondary osteoporosis, cardiomyopathy, and 
hypothalamic-pituitary-adrenal (HPA) axis suppression. Most of these conditions are well known, but HPA axis suppression has to date been understudied and under-reported.

The recommended treatment regimen for NS at diagnosis, according to the KDIGO guidelines (1), is with induction of prednisolone at $60 \mathrm{mg} / \mathrm{m}^{2} /$ day, or $2 \mathrm{mg} / \mathrm{kg} / \mathrm{day}$, (maximum $60 \mathrm{mg} /$ day) for 4-6 weeks. This will be followed by alternateday prednisolone given in single doses at $40 \mathrm{mg} / \mathrm{m}^{2}$ or 1.5 $\mathrm{mg} / \mathrm{kg}$ (maximum $40 \mathrm{mg}$ on alternate days), for 2-5 months with tapering of the dose. This is a longer duration of steroid therapy compared to the original ISKDC guideline (2) which consisted of 4 weeks induction and 4 weeks of $40 \mathrm{mg} / \mathrm{m}^{2}$ 3 days a week. Recently, PREDNOS trial (3) compared the pattern of disease relapse in patients receiving 8 weeks vs. extended 16 weeks of corticosteroids. There was no significant difference in time to first relapse in these two groups. They found that extended corticosteroid treatment reduced the healthcare resource use and only made a small improvement in quality of life. Treatment of relapse is different from initial presentation. Alternate day dosing of $0.1-1 \mathrm{mg} / \mathrm{kg}$ for at least 3 months is recommended in frequently relapsing and steroid dependent NS. The steroid weaning regimen may vary based on the individual patient's previous experiences with relapses, steroid dependency, frequency of relapses, steroid toxicity and the use of steroid sparing agent. Close monitoring is imperative to detect complications associated with prolonged use of highdose corticosteroids.

The physiological secretory rate of endogenous steroids in the intact HPA axis was $\sim 6 \mathrm{mg} / \mathrm{m}^{2} /$ day. Exogenous steroid doses were adjusted above this secretory rate $\left(8-10 \mathrm{mg} / \mathrm{m}^{2} /\right.$ day $)$ as their bioavailability is reduced by gastric acids and firstpass metabolism in the liver. High-dose steroids are defined as supraphysiological steroid levels. HPA axis suppression is dependent on the total duration, total cumulative dose, and potency of the steroid used (4).

Adrenal insufficiency can be primary, secondary, or tertiary. Primary adrenal insufficiency results from intrinsic adrenal cortex diseases. Secondary and tertiary adrenal insufficiencies are caused by impaired production or action of corticotrophin, and are collectively known as central adrenal insufficiency. Overall, the prevalence of secondary adrenal insufficiency is 150-280 per million inhabitants in a population (5) and the condition can occur in children on high-dose and prolonged steroid prescriptions (4).

Various stimuli may activate the HPA axis to maintain normal body homeostasis and to combat stress, such as that induced by infections and endotoxins (6),absence or reduced glucocorticoid negative feedback (7), and hypoglycemia. Suppression of this critical mechanism via endogenous or exogenous pathways may alter the body's adaptive processes, triggering a pathogenic cascade. Adrenal insufficiency is associated with significant morbidity and mortality when inadequately treated during periods of intercurrent illness (8).

Different methods of assessing the HPA axis function exist. The insulin tolerance test and the Standard Short Synacthen test (SSST) were frequently used, but their limited reliability, tediousness, and associated adverse events led to the low-dose Synacthen test (LDST) being the preferred test nowadays.
Moreover, LDST can detect mild degrees of adrenal insufficiency missed by SSST (9).

\section{MATERIALS AND METHODS}

\section{Study Population}

We identified 119 patients from the admissions list of the Pediatrics Institute of the Hospital Kuala Lumpur (Malaysia) between January 2017 and January 2018. We identified 119 patients as having steroid-sensitive NS, and enrolled 37 patients who fit the study inclusion criteria. Eligible patients had: (i) steroid-sensitive idiopathic NS; (ii) achieved remission; and (iii) been off steroids for 4-6 weeks. We excluded patients with: (i) steroid-resistant NS; or (ii) secondary NS. Figure 1 summarizes the selection process (Table $\mathbf{1}$ ).

\section{Data Collection}

We used a pre-defined standardized data collection sheet for extracting data that contained information on patients' socio-demographic information (gender, age, ethnicity), anthropometric measurements, age at diagnosis, total number of relapses, and total duration of steroid use before LDST.

We collected blood samples for morning serum cortisol and ACTH levels, and for the LDST after steroid discontinuation during a planned visit. We then examined the patients every 3 months for a year to monitor their disease progress, their growth parameters, and to detect relapses or steroid toxicity.

\section{LDST}

Synacthen was given intravenously $\left(0.5 \mu \mathrm{g} / \mathrm{m}^{2}\right)$ and serum cortisol levels were measured before and after the administration. The peak cortisol response at any time within $60 \mathrm{~min}$ should exceed $550 \mathrm{nmol} / \mathrm{L}$ (10). We used a lower Synacthen dose 0.5 $\mu \mathrm{g} / \mathrm{m}^{2}$ than the conventional $250 \mu \mathrm{g} / \mathrm{m}^{2}$ dose based on the observation that the low-dose ACTH stimulation test using $1 \mu \mathrm{g}$ of tetracosactrin can be used to detect mild secondary adrenal insufficiency (9). A cortisol increment at $30 \mathrm{~min}$ above the basal level is a measure of adrenal reserve and a low absolute level indicates adrenal insufficiency.

We educated parents about hydrocortisone replacement at times of illness or stress during transient adrenal insufficiency periods $(11,12)$. We informed parents to give oral hydrocortisone at three times the physiological replacement dose (30 $\mathrm{mg} / \mathrm{m}^{2} /$ day) divided into three equal doses) during moderate illnesses such as fever and minor injury (this is called hydrocortisone "stress dosing"). During severe illnesses such as serious injury or trauma, or for anesthesia for surgery, we prescribed intravenous hydrocortisone at 10 times the physiological replacement dose $\left(100 \mathrm{mg} / \mathrm{m}^{2} /\right.$ day divided into four equal doses) (11).

For study subjects who relapsed during the study period, treatment was instituted as per International Study of Kidney Disease in Children (ISKDC) guideline. Patients who developed an intercurrent illness during the study period were treated as per other children with NS. Assessment of the volume status, the need for antibiotics and steroid replacement therapy was on the discretion of the treating physician. 


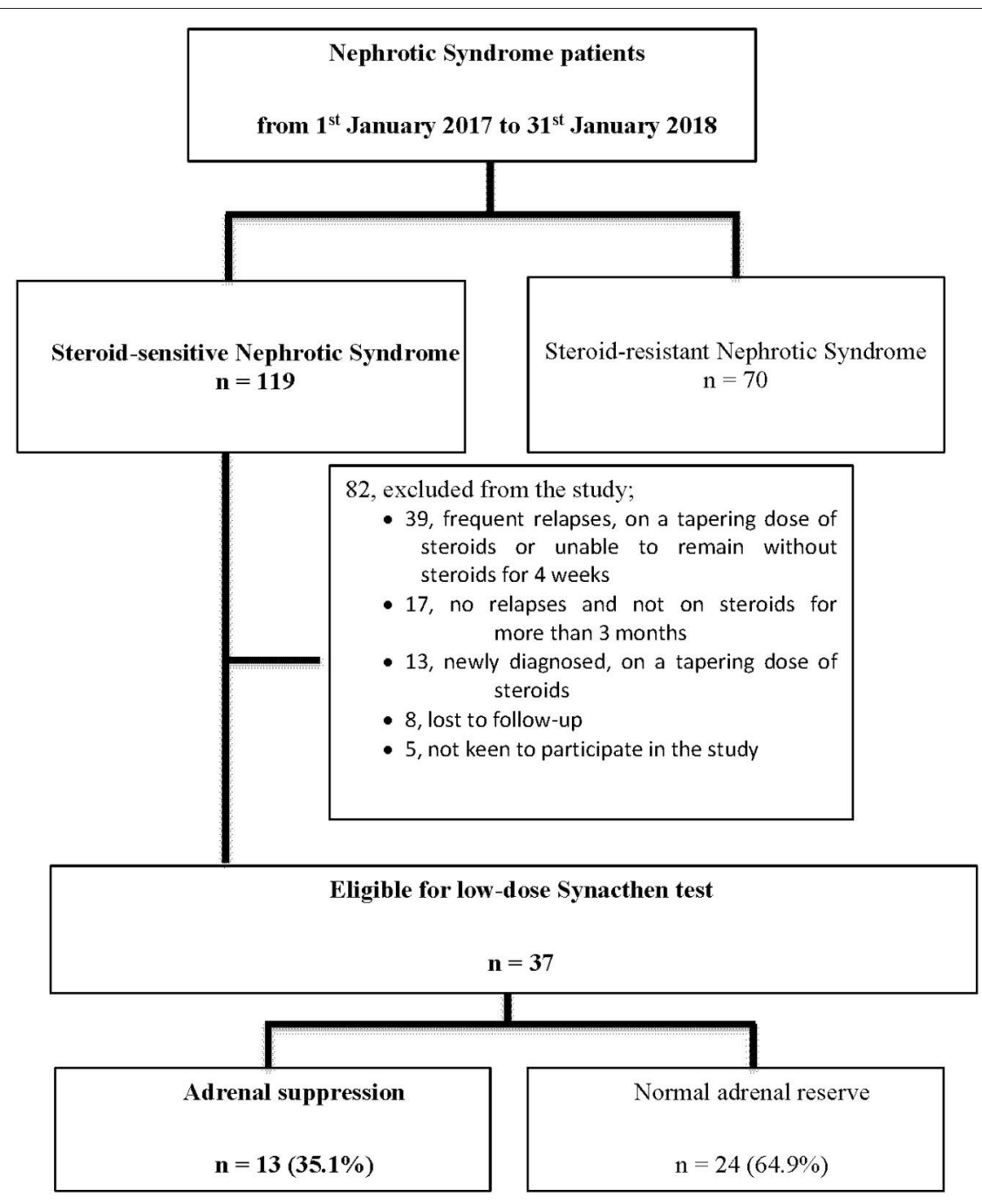

FIGURE 1 | Overview of the study flow.

TABLE 1 | Common definitions in nephrotic syndrome.
Remission

Relapse

Frequent relapses

Steroid dependence
Steroid resistance
Urine albumin nil or trace for three consecutive days

Urine albumin $3+$ or more for three consecutive days

Two or more relapses in the initial 6-month period or more than three relapses in any 12 months

Two consecutive relapses when on alternate day steroid therapy or within 14 days of its discontinuation

Absence of remission despite therapy with daily prednisolone at a dose of $60 \mathrm{mg} / \mathrm{m}^{2} /$ day

\section{Ethical Considerations}

We registered this study with the National Medical Research Register (NMRR) under the identification number NMRR-161427-30586 (IIR). The Medical Research Ethics Committee (MREC), the University Malaya Medical Centre (UMMC) approved the study under the registration number MREC UMMC ID: 2016816-4142. This study was supported by a grant from the University Malaya Research Fund Assistance (BKP0342015). We obtained written informed consent from all parents or guardians of the patients prior to starting the study. All children enrolled were also required to sign an assent form or to agree verbally. We performed all tests in accordance with approved guidelines.

\section{Statistical Analysis}

We used descriptive statistics to compare baseline characteristics between children with adrenal suppression and those with normal adrenal function. We expressed numerical data as means and standard deviations, and tabulated categorical variables as predicted numbers and percentages. We first used simple logistic regression analyses to determine unadjusted associations of factors of interest, and then applied multivariate analyses using the logistic regression model to identify predictors of HPA 
insufficiency. We performed data analyses using the Statistical Package for Social Science software version 23.0. The data that support the findings of this study are available upon request from the corresponding author. The data are not publicly available due to privacy or ethical restrictions.

\section{RESULTS}

Between 1st January 2017 and 31st January 2018, a total of 189 patients received treatment for NS in the Pediatric Institute of the Hospital Kuala Lumpur in Malaysia. Of 189 patients, 70 (37\%) were steroid-resistant and 119 patients were steroid-sensitive, but only $31 \%$ of the patients (37 of 119 ) fit the eligibility criteria for enrolment; we excluded 69 patients, lost eight to follow-up, and encountered five patients who chose not to participate in the study (Figure 1).

Our study population showed a greater preponderance of males, with a male to female ratio of 3.6:1. The majority of patients were of Malay ethnicity and consisted of 26 patients (70.3\%) and the rest were Chinese and Indians (in almost equal proportion). The mean age at diagnosis of NS was 3.38 years $( \pm 2.28)$, and the mean age at LDST was 9.47 years $( \pm 3.73)$. Thirty-four out of 37 patients $(91.9 \%)$ were 5 years old or younger. The mean duration of the NS was 6.09 years ( \pm 3.44 ), with $21 / 37(43.2 \%)$ having the illness for more than 5 years (Table 2).

Almost two thirds of the patients, 62.2\% (23/37), had evidence of steroid toxicity. However, only 54\% (20/37) had received a steroid-sparing agent (SSA). We possess no data that can explain this discrepancy. The SSAs prescribed were cyclophosphamide (13), levamisole (12), cyclosporine (7), rituximab (3), mycophenolic acid (1), and tacrolimus (1). Four patients received three or more types of SSA, six patients received two types of SSA, and the remaining 10 patients received a single agent. We categorized the steroid toxicities according to the affected system: immunosuppression; cardiovascular (hypertension); eye involvement (cataract, glaucoma); and musculoskeletal (short stature, cushingoid features, and skin striae). Eight out of 37 patients (21.6\%) had frequent relapses and $20(54.1 \%)$ patients were steroid dependent.

Thirteen out of 37 patients (35.1\%) had HPA axis suppression. All of them were younger than 5 years of age and $76.9 \%$ were boys $(n=10 / 13)$. The mean durations of steroid usage were 66 $( \pm 121.25)$ weeks in those who developed HPA axis suppression and $30( \pm 35.31)$ weeks in those who did not. Ten of those patients with HPA axis suppression (76.9\%) were steroid dependent.

We found that children with a younger age (mean age at diagnosis of 2.54 years) were more likely to develop HPA axis suppression than older children (95\% CI, 0.567-0.990). Steroiddependent patients were six times more likely to develop HPA axis suppression than to maintain normal HPA axis function (95\% CI, 1.06-29.34) (Table 3).

The mean basal plasma cortisol concentration was significantly higher by $40 \%$ in patients with a normal adrenal response than in patients with a suppressed adrenal response [303.92 ( \pm 133.99$)$ vs. $215.69( \pm 102.61) \mathrm{nmol} / \mathrm{L}, p=0.012]$.
TABLE 2 | Demographic and clinical characteristics of patients with normal HPA axis and HPA axis suppression.

\begin{tabular}{|c|c|c|c|}
\hline \multicolumn{2}{|c|}{ Characteristics } & \multirow{2}{*}{$\begin{array}{c}\text { Normal HPA axis } \\
(\boldsymbol{n}=\mathbf{2 4 )}(\mathbf{6 4 . 9} \%)\end{array}$} & \multirow{2}{*}{$\begin{array}{c}\text { HPA axis } \\
\text { suppression } \\
(\boldsymbol{n}=\mathbf{1 3})(\mathbf{3 5 . 1} \%) \\
10(76.9)\end{array}$} \\
\hline Gender & Male & & \\
\hline & Female & $5(20.8)$ & $3(23.1)$ \\
\hline \multirow[t]{3}{*}{ Race } & Malay & $16(66.7)$ & $10(76.9)$ \\
\hline & Chinese & $5(20.8)$ & $1(7.7)$ \\
\hline & Indian & $3(12.5)$ & $2(15.4)$ \\
\hline \multicolumn{2}{|c|}{ Age at diagnosis, years, mean $\pm \mathrm{SD}^{*}$} & $3.83 \pm 2.69$ & $2.54 \pm 0.80$ \\
\hline \multirow[t]{3}{*}{ Age at diagnosis } & $0-5$ years & $21(87.5)$ & $13(100)$ \\
\hline & $6-11$ years & $2(8.3)$ & $0(0.0)$ \\
\hline & $12-18$ years & $1(4.2)$ & $0(0.0)$ \\
\hline \multicolumn{2}{|c|}{ Age at LDST, years, mean $\pm \mathrm{SD}^{\star}$} & $10.44 \pm 4.25$ & $7.67 \pm 1.32$ \\
\hline \multirow[t]{3}{*}{ Age at LDST } & $0-5$ years & $5(20.8)$ & $2(15.4)$ \\
\hline & $6-11$ years & $10(41.7)$ & $11(84.6)$ \\
\hline & $12-18$ years & $9(37.5)$ & $0(0.0)$ \\
\hline \multicolumn{2}{|c|}{ Duration of illness, years, mean $\pm \mathrm{SD}^{*}$} & $6.61 \pm 3.99$ & $5.13 \pm 1.86$ \\
\hline \multirow[t]{2}{*}{ Duration of illness } & $\leq 5$ years & $10(41.7)$ & $6(46.2)$ \\
\hline & $>5$ years & $14(58.3)$ & 7 (53.8) \\
\hline \multicolumn{2}{|c|}{$\begin{array}{l}\text { Duration of steroid use, weeks, } \\
\text { mean } \pm \mathrm{SD}^{\star}\end{array}$} & $30.54 \pm 35.31$ & $66.05 \pm 121.25$ \\
\hline \multirow[t]{2}{*}{ Duration of steroid use } & $<20$ weeks & $13(54.2)$ & 7 (53.8) \\
\hline & $\geq 20$ weeks & $11(45.8)$ & $6(46.2)$ \\
\hline \multicolumn{2}{|c|}{$\begin{array}{l}\text { The dose of steroid use, } \mathrm{mg} / \mathrm{m}^{2} / \text { days, } \\
\text { mean }(\mathrm{SD})^{\star}\end{array}$} & $22.37 \pm 8.30$ & $25.63 \pm 11.36$ \\
\hline \multirow[t]{2}{*}{ Steroid-dependent } & No & $14(58.3)$ & $3(23.1)$ \\
\hline & Yes & $10(41.7)$ & 10 (76.9) \\
\hline \multirow[t]{2}{*}{ Frequent relapse } & No & 20 (83.3) & $9(69.2)$ \\
\hline & Yes & $4(16.7)$ & $4(30.8)$ \\
\hline \multirow[t]{2}{*}{ Steroid toxic } & No & 8 (33.3) & $6(46.2)$ \\
\hline & Yes & $16(66.7)$ & 7 (53.8) \\
\hline \multirow{2}{*}{$\begin{array}{l}\text { Use of steroid-sparing } \\
\text { agent (SSA) }\end{array}$} & No & 9 (37.5) & $8(61.5)$ \\
\hline & Yes & $15(62.5)$ & 5 (38.5) \\
\hline \multirow[t]{2}{*}{$\begin{array}{l}\text { Immuno-suppression } \\
\text { prior to LDST }\end{array}$} & $\begin{array}{l}\text { Prednisolone } \\
\text { alone }\end{array}$ & $19(79.2)$ & $11(84.6)$ \\
\hline & $\begin{array}{l}\text { Combination } \\
\text { with SSA }\end{array}$ & $5(20.8)$ & $2(15.4)$ \\
\hline \multirow[t]{2}{*}{ Comorbid diseases } & No & $17(70.8)$ & $11(84.6)$ \\
\hline & Yes & 7 (29.2) & $2(15.4)$ \\
\hline \multicolumn{2}{|l|}{$\begin{array}{l}\mathrm{ACTH}, \mathrm{pmol} / \mathrm{L} \\
\text { mean } \pm \mathrm{SD}\end{array}$} & $20.52 \pm 14.20$ & $40.92 \pm 85.14$ \\
\hline \multirow[t]{2}{*}{ ACTH Result } & Normal & $22(91.7)$ & 10 (76.9) \\
\hline & Abnormal & $2(8.3)$ & $3(23.1)$ \\
\hline
\end{tabular}

${ }^{*} S D$, standard deviation.

After the injection of $0.5 \mu \mathrm{g} / \mathrm{m}^{2}$ Synacthen, both groups of patients demonstrated serum cortisol peaks at $20 \mathrm{~min}$. The mean 20-min peak serum cortisol concentration was lower in the children with suppressed responses than in those with 
normal responses; this difference, however, was not statistically significant $[467.54( \pm 69.16)$ and $630.33( \pm 97.86)$, respectively, $p=0.869$ ] (Figure 2).

\section{DISCUSSION}

We analyzed cortisol levels in patients with steroid-sensitive NS using LDST and confirmed that 13 of them (35.1\%) had HPA axis suppression. Multivariate analyses showed that younger age at diagnosis and steroid dependency were the two significant factors associated with HPA axis suppression. We defined HPA axis suppression as cortisol levels $<550 \mathrm{nmol} / \mathrm{L}$ despite stimulation. This definition may help to anticipate adverse outcomes associated with inappropriate cortisol responses during "stress periods" in children on steroid therapy.

The duration of steroid usage in children with NS varies with the frequency of relapses, steroid dependency, presence of steroid toxicity, and different medical practices. In our center, we administer steroids as per the ISKDC guideline. Case-to-case evaluations are frequent as some patients maintain remission states and avoid relapses when given prolonged steroid courses.

The HPA axis functions as a complex neuroendocrine feedback mechanism crucial during stress adaptation (14); it is influenced by circadian and ultradian rhythms (15). Animal

TABLE 3 | Multivariate analysis for children with nephrotic syndrome on corticosteroid treatment.

\begin{tabular}{lccccc}
\hline \multicolumn{1}{c}{ Variables } & & $\boldsymbol{B}^{*}$ & Df** $^{* *}$ & $\boldsymbol{p}$-value & Adjusted + OR (95\% $\left.{ }^{++} \mathbf{C l}\right)$ \\
\hline Age at diagnosis & & -0.288 & 1 & 0.043 & $0.749(0.567-0.990)$ \\
Steroid-dependent & No & 1.719 & 1 & 0.042 & $5.58(1.06-29.34)$ \\
& Yes & & & & \\
& & & &
\end{tabular}

${ }^{\star} B$, beta; ${ }^{\star \star} D f$, degrees of freedom; ${ }^{+} O R$, odd ratio; ${ }^{++} C l$, confidence interval; $L D S T$, low-dose Synacthe $n$ test. studies have shown that the HPA axis regulates the secretion of glucocorticoids, which have dominant effects in regulating cardiovascular, metabolic, cognitive, and immunological states $(13,16,17)$. The paraventricular nuclei (PVN) of the hypothalamus initiate axis activation $(18,19)$. Exposure to stressors stimulates the secretion of corticotrophin-releasing hormone $(\mathrm{CRH})$, and this hormone eventually stimulates the pituitary gland to secrete adrenocorticotropic hormone (ACTH). ACTH in turn binds to its receptors on the adrenal gland and induces cortisol secretion $(20,21)$, which inhibits $\mathrm{ACTH}$ and $\mathrm{CRH}$ production (negative feedback mechanism), in a manner similar to that in children with excess exogenous glucocorticoids (22).

Children with NS receive supraphysiologic doses of steroids that may potentially inhibit cortisol production. When this inhibition lasts longer than the duration of the corticosteroid exposure, it is called adrenal suppression. Although the effect may be transient, it can result in significant morbidity during periods of physiologic stress (23). In children receiving high-dose steroids, adrenal suppression is not apparent and clinicians need to be aware that abrupt withdrawal may trigger adrenal crises $(4,22)$.

The suppression of the HPA axis can occur after a single dose of steroid, but it typically recovers quickly. However, the longterm use of systemic corticosteroids may take a long time to recover (24). Studies have looked at the effects of corticosteroid use on the HPA axis and at the corresponding recovery times. The recovery time depends on the glucocorticoid potency and its types, the duration of therapy, and the weaning protocols; therefore, estimations are difficult, and comparisons between studies are complex also because of the different diagnostic tests used to assess the adrenal function.

In our study, the local prevalence of adrenal suppression in children with NS 4-6 weeks after steroid discontinuation was $35.1 \%$. This figure is lower than that reported in a study by Abeyagunawardena et al. (25), which showed that 20 of $32(62.5 \%)$ children on alternate-day prednisolone for

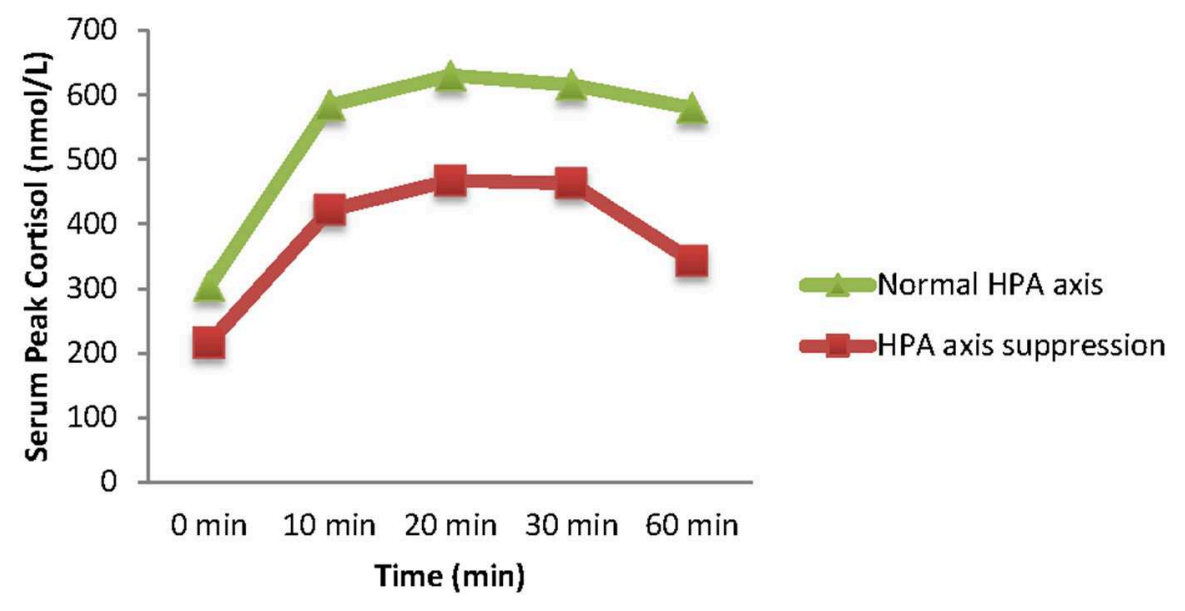

FIGURE 2 | Serum peak cortisol concentrations (means) from baseline (time 0) following stimulation with $0.5 \mu \mathrm{g} / \mathrm{m}^{2}$ Synacthen (10, 20, 30, and 60 timepoints). 
steroid-dependent NS had HPA axis suppression. Furthermore, their cut-off cortisol level to diagnose adrenal suppression was found to be $<500 \mathrm{nmol} / \mathrm{L}$. Mantan et al. (26) also studied children on low dose steroids and 28 of 70 children had adrenal suppression. Diagnosis is based on a single early morning dose of serum cortisol. Those at a risk of acquiring adrenal suppression in his study were mainly frequent relapsers and steroid resistant NS.

The variety of investigations used and different cut-off values to examine the HPA axis are potential caveats concerning the validity of the assessment results. Recently, Mongioi et al. (27) studied the accuracy of LDST in 103 adults. All of them had primary AI or hypothalamic-pituitary diseases. Those receiving steroids were excluded. The receiver operating characteristic curve showed $100 \%$ sensitivity and $67.3 \%$ specificity when 500 $\mathrm{nmol} / \mathrm{L}$ was used as the serum cortisol cut-off value. Our study, however, is based on the study done by Tordjman et al. (9), which used $550 \mathrm{nmol} / \mathrm{L}$ of serum cortisol as the cut-off value in LDST, resulting in $100 \%$ sensitivity and $89 \%$ specificity.

We found steroid toxicity in $62.2 \%$ of our cohort, suggesting that predicting which patients are at risk of developing adrenal crisis is impossible based on steroid toxicity alone. In a resource limited setting, conducting screening tests for HPA axis suppression in every patient on corticosteroid treatment is additionally unfeasible. Therefore, predicting patients who warrant screening for adrenal suppression is important. Based on our study findings, patients younger than 5 years, and who are steroid-dependent, should be screened for adrenal suppression by measuring both a morning serum cortisol level and an LDST. Identifying children at risk for adrenal suppression early would reduce the burden of illness in terms of morbidity, mortality, and cost of care.

We acknowledge the limitations of our study. We had no data on the frequency of hospital admissions, severity of intercurrent

\section{REFERENCES}

1. Kidney Disease Improving Global Outcome. Treatment of the Initial Episode of Steroid Sensitive Nephrotic Syndrome (KDIGO Guideline No. 3.1) (2012). Retrieved from: https://kdigo.org

2. Tarshish P, Tobin JN, Bernstein J Edelmann CM. Prognostic significance of the early course of minimal change nephrotic syndrome: report of the International Study of Kidney Disease in Children. JASN. (1997) 8:769-76.

3. Webb NJA, Woolley RL, Lambe T, Frew E, Brettell EA, Barsoum EN, et al. Long term tapering versus standard prednisolone treatment for first episode of childhood nephrotic syndrome : phase III randomised controlled trial and economic evaluation. BMJ. (2019) 365:11800. doi: 10.1136/bmj.11800

4. Gupta P, Bhatia V. Corticosteroid physiology and principles of therapy. Indian J Pediatr. (2008) 75:1039-44. doi: 10.1007/s12098-008-0208-1

5. Laureti S, Vecchi L, Santeusanio F, Falorni A. Is the prevalence of Addison's disease underestimated? J Clin Endocrinol Metab. (1999) 84:1762 doi: 10.1210/jcem.84.5.5677-7

6. Beishuizen A, Thijs LG. Endotoxin and the hypothalamo-pituitary-adrenal (HPA) axis. J Endotoxin Res. (2003) 9:3-24 doi: 10.1179/096805103125001298

7. Smith SM, Vale WW. The role of hypothalamic-pituitary-adrenal axis in neuroendocrine responses to stress. Dialogues Clin Neurosci. (2006) 8:383-95.

8. Quinkler M, Johannsson G, Falorni A, Skrtic S, Lennern H, Monson JP, et al. Adrenal insufficiency : review of clinical outcomes with current glucocorticoid illnesses, or recovery rates to compare between patients with HPA axis suppression and those without HPA axis suppression. We also failed to examine the recovery periods in children with HPA axis suppression.

In conclusion, a life-threatening HPA axis suppression may go unnoticed without proper screening. A normal early morning cortisol level (275-555 nmol/L) does not rule out adrenal insufficiency in children with steroid-sensitive NS. Further screening with LDSTs may be warranted, particularly in children younger than 5 years of age at diagnosis.

\section{DATA AVAILABILITY STATEMENT}

The datasets analyzed in this article are not publicly available. Requests to access the datasets should be directed to Karmila Abu Bakar, karmila@um.edu.my.

\section{ETHICS STATEMENT}

The studies involving human participants were reviewed and approved by NMRR. Written informed consent to participate in this study was provided by the participants' legal guardian/next of kin. Written informed consent was obtained from the individual(s), and minor(s)' legal guardian/next of kin, for the publication of any potentially identifiable images or data included in this article.

\section{AUTHOR CONTRIBUTIONS}

All authors worked together in designing the study, getting ethics approval, recruiting patients, performing the low-dose synacthen test, analyzing the data, and writing up the paper.

replacement therapy. Clin Endocrinol. (2015) 82:2-11. doi: 10.1111/cen. 12603

9. Tordjman K, Jaffe A, Grazas N, Apter C, Stern N. The role of the low dose (1 microgram) adrenocorticotropin test in the evaluation of patients with pituitary diseases. J Clin Endocrinol Metab. (1995) 80:1301-5. doi: 10.1210/jcem.80.4.7714104

10. Gonc EN, Kandemir N, Kinik ST. Significance of low-dose and standard-dose ACTH tests compared to overnight metyrapone test in the diagnosis of adrenal insufficiency in childhood. Horm Res. (2003) 60:191-7 doi: $10.1159 / 000073232$

11. Shulman DI, Palmert MR, Kemp SF. Adrenal insufficiency: still a cause of morbidity and death in childhood. Pediatrics. (2007) 119:e484-94. doi: $10.1542 /$ peds.2006-1612

12. Merke DP, Bornstein SR. Congenital adrenal hyperplasia. Lancet. (2005) 365:2125-36. doi: 10.1016/S0140-6736(05)66736-0

13. McEwen BS. Physiology and neurobiology of stress and adaptation: central role of the brain. Physiol Rev. (2007) 87:873-904. doi: 10.1152/physrev.00041.2006

14. Herman JP, Mcklveen JM, Ghosal S, Kopp B, Wulsin A, Makinson R, et al. Regulation of the hypothalamic-pituitary-adrenocortical stress response. Compr Physiol. (2016) 6:603-21. doi: 10.1002/cphy.c150015

15. Walker JJ, Terry JR, Lightman SL. Origin of ultradian pulsatility in the hypothalamic - pituitary - adrenal axis. Proc Biol Sci. (2010) 277:1627-33. doi: $10.1098 / \mathrm{rspb} .2009 .2148$ 
16. Chrousos GP. The hypothalamic-pituitary-adrenal axis and immunemediated inflammation. $N$ Engl J Med. (1995) 332:1351-62. doi: 10.1056/NEJM199505183322008

17. de Kloet ER, Joels M, Holsboer F. Stress and the brain: from adaptation to disease. Nat Rev Neurosci. (2005) 6:463-75. doi: 10.1038/nrn1683

18. Vale W, Spiess J, Rivier C, Rivier J. Characterization of a 41-residue ovine hypothalamic peptide that stimulates secretion of corticotropin and beta-endorphin. Science. (1981) 213:1394-7. doi: 10.1126/science.62 67699

19. Rivier C, Vale W. Modulation of stress-induced ACTH release by corticotropin-releasing factor, catecholamines and vasopressin. Nature. (1983) 305:325-7. doi: 10.1038/305325a0

20. Mountjoy KG, Robbins LS, Mortrud MT, Cone RD. The cloning of a family of genes that encode the melanocortin receptors. Science. (1992) 257:1248-51. doi: 10.1126/science.1325670

21. Cone RD, Lu D, Koppula S, Vage DI, Klungland H, Boston B, et al. The melanocortin receptors: agonists, antagonists, and the hormonal control of pigmentation. Recent Prog Horm Res. (1996) 51:287-317.

22. Paragliola RM, Papi G, Pontecorvi A, Corsello SM. Treatment with synthetic glucocorticoids and the hypothalamus-pituitary-adrenal axis. Int J Mol Sci. (2017) 18:2201. doi: 10.3390/ijms18102201

23. Ahmet A, Brienza V, Tran A, Lemieux J, Aglipay M, Barrowman N, et al. Frequency and duration of adrenal suppression following glucocorticoid therapy in children with rheumatic diseases. Arthritis Care Res. (2017) 69:1224-30. doi: 10.1002/acr.23123
24. Sperling MA. Pediatric Endocrinology E-Book. Elsevier Health Sciences (2014).

25. Abeyagunawardena AS, Hindmarsh P, Trompeter RS. Adrenocortical suppression increases the risk of relapse in nephrotic syndrome. Arch Dis Child. (2007) 92:585-8. doi: 10.1136/adc.2006.1 08985

26. Mantan M, Grover R, Kaushik S, Yadav S. Adrenocortical suppression in children with nephrotic syndrome treated with low-dose alternate day corticosteroids. Indian J Nephrol. (2018) 28:203-8. doi: 10.4103/ijn. IJN_80_17

27. Mongioì LM, Condorelli RA, Barbagallo F, Cannarella R, La Vignera S, Calogero AE. Accuracy of the low-dose ACTH stimulation test for adrenal insufficiency diagnosis: a re-assessment of the cut-off value. J Clin Med. (2019) 8:806. doi: $10.3390 / \mathrm{jcm} 8060806$

Conflict of Interest: The authors declare that the research was conducted in the absence of any commercial or financial relationships that could be construed as a potential conflict of interest.

Copyright (C) 2020 Abu Bakar, Khalil, Lim, Yap, Appadurai, Sidhu, Lai, Anuar Zaini, Samingan and Jalaludin. This is an open-access article distributed under the terms of the Creative Commons Attribution License (CC BY). The use, distribution or reproduction in other forums is permitted, provided the original author(s) and the copyright owner(s) are credited and that the original publication in this journal is cited, in accordance with accepted academic practice. No use, distribution or reproduction is permitted which does not comply with these terms. 